\title{
Burden of migraine and unmet needs from the patients' perspective: a survey across 11 specialized headache clinics in Korea
}

\author{
Byung-Kun Kim", Min Kyung Chu², Soo Jin Yư ${ }^{3}$, Grazia Dell'Agnello ${ }^{4}$, Jeong Hee $\mathrm{Han}^{3}$ and Soo-Jin Cho ${ }^{5^{*}}$ (D)
}

\begin{abstract}
Background: Migraine is a neurological, primary headache disorder affecting more than 1 billion people worldwide, with a multi-faceted burden that can significantly impact the everyday life of a patient, both during and between attacks. However, studies on patient awareness, burden, and clinical management of migraine in Korea are limited and outdated. The aim of this study was to comprehensively investigate the current difficulties and unmet needs that Korean patients with migraine encounter from their perspective.

Methods: A total of 207 patients with episodic or chronic migraine aged between 15 and 76 years, completed a survey designed to cover the following topics: diagnosis, understanding of the disease, treatment experience, disability, and quality of life. Patients were recruited by their neurologists from 11 specialized headache clinics in Korea and completed the survey between 22 July and 19 August 2019. Validated scales such as the Migraine Disability Assessment (MIDAS) questionnaire and Migraine-Specific Quality of Life Questionnaire version 2.1 (MSQv2.1) were used to assess levels of disability and quality of life, respectively, in patients.

Results: On average, it took 10.1 years from onset of symptoms to diagnosis and a mean of 3.9 hospitals were visited for treatment prior to the patient's current hospital. There was a lack of understanding among respondents about migraine, with $55.6 \%$ believing that unilateral headache is a unique feature of migraine compared with other headache disorders. On average, high levels of disability and poor quality of life were reported by patients, as assessed by MIDAS and MSQv2.1, respectively, but only $23.7 \%$ had regularly taken preventive medication in the past. Overall satisfaction with previous doctor-patient relationships was reported by $29.5 \%$ of respondents, and satisfaction with preventive and acute medications by only $40.8 \%$ and $27.1 \%$ of the respondents, respectively.
\end{abstract}

Conclusion: Korean patients with migraine experience significant disability and reduced quality of life as a result of the disease and have clear unmet needs in terms of diagnosis, understanding of the disease, and disease management including treatment.

Keywords: Migraine, Korea, Burden, Disability, MIDAS, MSQv2.1, Diagnosis, Treatment, Patient survey

\footnotetext{
* Correspondence: dowonc@naver.com

${ }^{5}$ Department of Neurology, Dongtan Sacred Heart Hospital, Hallym University

College of Medicine, Hwaseong, South Korea

Full list of author information is available at the end of the article
}

\section{$\triangle B M C$}

(C) The Author(s). 2021, corrected publication 2021. Open Access This article is licensed under a Creative Commons Attribution 4.0 International License, which permits use, sharing, adaptation, distribution and reproduction in any medium or format, as long as you give appropriate credit to the original author(s) and the source, provide a link to the Creative Commons licence, and indicate if changes were made. The images or other third party material in this article are included in the article's Creative Commons licence, unless indicated otherwise in a credit line to the material. If material is not included in the article's Creative Commons licence and your intended use is not permitted by statutory regulation or exceeds the permitted use, you will need to obtain permission directly from the copyright holder. To view a copy of this licence, visit http://creativecommons.org/ licenses/by/4.0/. The Creative Commons Public Domain Dedication waiver (http://creativecommons.org/publicdomain/zero/1. 0/) applies to the data made available in this article, unless otherwise stated in a credit line to the data. 


\section{Background}

Migraine is a disabling, neurological disease that can severely impact every aspect of an individual's life, yet is still under-recognized, under-diagnosed, and undertreated [1]. Migraine affects $11.6 \%$ of the world's population [2], or approximately 1.3 billion people [3] and is the leading cause of disability in persons under 50 years of age [4]. Migraine and the accompanying symptoms can be significantly burdensome to patients, impacting daily functioning ability and quality of life both during and between migraine attacks [5-9]. Non-headache symptoms and co-morbid disorders such as depression and anxiety are common with migraine and can further hinder management of the disease [7, 10-14]. Migraine has a two- to three-fold higher prevalence in women compared with men $[2,15]$. The median prevalence of migraine in the Asia-Pacific region is 9.1\% [16]. In South Korea, the estimated prevalence is approximately 8 to $9 \%$ in women and $3 \%$ in men $[11,17,18]$, and $6 \%$ overall $[16,18,19]$. The age group with the highest prevalence is $40-49$ followed by $30-39$ years of age $[18,19]$. A recent study on sex differences in migraine prevalence among Korean patients showed that in women, prevalence is highest in the 30-39 age group followed by $40-$ 49 [11].

Studies in East Asia, including South Korea, have demonstrated that migraine is associated with a significant burden for patients. Migraine attacks and accompanying symptoms such as nausea, vomiting, and sensory disturbances impact significantly on daily activities (work, school, chores) and overall quality of life [18-25]. In addition, there are unmet needs for East Asian patients in relation to diagnosis and treatment, owing in part to lack of the following: sufficient and appropriate diagnosis, disease awareness, and use of prescription medication [22, 23, 25, 26]. Lack of diagnosis and disease awareness could in turn contribute to an underestimated prevalence. A survey was conducted across eight Asian countries, including South Korea, in which 222 neurologists and 3177 patients participated. The results were published in 2008 and revealed that $36 \%$ of patients had received emergency treatment for migraine. Eighty-four percent of patients were taking acute medication with $40 \%$ of those patients dissatisfied with the relief obtained within $2 \mathrm{~h}$ of taking the medication. Physicians reported that $71 \%$ of their patients with migraine were not taking preventive treatment, and recommended that $68 \%$ of those patients were in need of such treatment [23].

The available literature on patient awareness, burden, and clinical management of migraine in Korea is limited and outdated. Such information is crucial in ensuring a patient-centric approach in the appropriate diagnosis and treatment of affected individuals. A survey was designed to comprehensively investigate the more current difficulties and unmet needs that Korean patients face regarding migraine diagnosis, awareness, treatment, and their perceived disability and quality of life.

\section{Materials and methods \\ Patient selection}

First-visit patients diagnosed with episodic or chronic migraine according to International Classification of Headache Disorders (ICHD) criteria, and with previous treatment experience, were recruited from the following 11 specialized headache clinics in Korea: Nowon Eulji Medical Center, Gangbuk Samsung Hospital, Korea University Guro Hospital, Dongtan Sacred Heart Hospital, Bundang Jesaeng Hospital, Samsung Medical Center, Seoul Paik Hospital, Seoul Medical Center, Severance Hospital, Uijeongbu St. Mary's Hospital, and Ilsan Paik Hospital. Conducting of surveys is subject to Institutional Review Board exemption in Korea, but approval is required for preparation of a publication. Prior to participation, patients provided written consent to use the results of the survey for statistical purposes. Approval for preparation of this manuscript was granted by the Institutional Review Board of Nowon Eulji Medical Center (Approval No 2020-06-009). Survey data were handled confidentially, and anonymity of respondents was maintained throughout the study.

\section{Survey design and outcomes}

The survey was created in collaboration with Hankook Research Ltd. and included questions on the following in relation to migraine specifically: history and diagnosis, knowledge about migraine, utilization of medical services, disability and quality of life, unmet treatment needs regarding disease management, and experience with preventive and acute medications prior to visiting their current hospital. Validated scales such as the Migraine Disability Assessment (MIDAS) questionnaire [27] and the Migraine-Specific Quality of Life Questionnaire version 2.1 (MSQv2.1) [28] were used to assess the level of disability and quality of life of patients, respectively. The MIDAS was developed to assess headacherelated disability with the aim of improving migraine care [27]. It is a self-administered questionnaire designed to quantify headache-related disability over a 3-month period. This questionnaire consists of five questions pertaining to time or productivity lost, as well as the limited ability to participate in work or school, household chores, family events, and social or leisure activities. The question responses are in the form of number of days affected in the past 3 months. The total MIDAS score, which is the summation of the answers for each question, corresponds to a grade of migraine-related disability (0-5, Grade I, minimal or infrequent disability; 6-10, Grade II, mild or infrequent disability; 11-20, Grade III, 
moderate disability; $\geq 21$, Grade IV, severe disability). The MSQv2.1 measures quality of life among migraine patients during the previous 4 weeks [28]. It has three scales assessing unique quality of life domains: Role Function-Restrictive (RR), Role Function-Preventive (RP), and Emotional Function (EF) which consist of different items to assess. These items include; limitations of patients' performance of normal activities (for RR), interruptions of patients' performance of normal activities (for RP) and impact of migraine on the respondents' emotions, such as frustration or helplessness (for $\mathrm{EF}$ ). The item responses range from 1 to $6(1=$ none of the time; $2=$ a little bit of time; $3=$ some of the time; $4=\mathrm{a}$ good bit of the time; $5=$ most of the time; $6=$ all of the time). All items are reverse-coded and standardized to a 0 to 100 scale. Thus, higher scale scores indicate better migraine-related quality of life [29].

Data were described descriptively. Categorical variables were reported using percentage. Numerical variables were reported using the mean and either standard deviation (SD) or standard error (SE), calculated using Microsoft Excel for Office 365. No formal statistical analyses were conducted.

\section{Completion of survey}

The total number of patients who completed the survey was 207. The survey was completed by the patient in an approximately $20 \mathrm{~min}$ period, in the presence of an educated guide. Surveys were completed between 22 July and 19 August 2019.

\section{Results}

\section{Respondent demographics}

Respondent demographics are shown in Table 1. Out of the 207 respondents, the average age was 45.5 years old and the category with the largest number of patients was $40-49$ years of age, followed by $50-59,30-39,60+$, and $10-29$. Overall, the vast majority were female, mean age of onset of migraine was 27.7 years, and mean time from first symptoms to diagnosis was 10.1 years. Mean age of onset and mean time from first symptoms to diagnosis varied significantly between age groups. The overall mean duration of disease was 17.7 years. The overall mean number of headache days per month was 12.4 and the majority of patients had episodic migraine (Table 1).

\section{Knowledge about migraine}

With regards to knowledge about migraine, less than half of patients overall believed that they had some level of knowledge (Fig. 1). When questioned about differences between migraine and other headache disorders, few patients overall believed that migraine was different from other headache disorders in terms of aura, pathomechanism, and accompanying symptoms. Fewer patients in the older age groups compared with younger age groups believed that aura and accompanying symptoms were unique features of migraine. Overall,

Table 1 Respondent demographics

\begin{tabular}{|c|c|c|c|c|c|c|}
\hline & $10-29^{a}$ & $30-39$ & $40-49$ & $50-59$ & $60+b$ & $\begin{array}{l}\text { Overall - all age groups } \\
\text { combined }\end{array}$ \\
\hline \multicolumn{7}{|l|}{ Variable } \\
\hline Number of patients, $N$ (\% of total patients) & $\begin{array}{l}25 \\
(12.1 \%)\end{array}$ & $\begin{array}{l}40 \\
(19.3 \%)\end{array}$ & $\begin{array}{l}63 \\
(30.4 \%)\end{array}$ & $\begin{array}{l}47 \\
(22.7 \%)\end{array}$ & $\begin{array}{l}32 \\
(15.5 \%)\end{array}$ & $207(100 \%)$ \\
\hline Female, $n$ (\% of age group) & $\begin{array}{l}15 \\
(60.0 \%)\end{array}$ & $\begin{array}{l}33 \\
(82.5 \%)\end{array}$ & $\begin{array}{l}55 \\
(87.3 \%)\end{array}$ & $\begin{array}{l}45 \\
(95.7 \%)\end{array}$ & $\begin{array}{l}27 \\
(84.4 \%)\end{array}$ & $175(84.5 \%)$ \\
\hline Mean age, years (SD) & $24.3(4.1)$ & $34.7(3.2)$ & $44.7(2.9)$ & $54.3(2.7)$ & $64.0(3.5)$ & $45.5(12.6)$ \\
\hline Mean age of onset, years (SD) & $17.0(3.5)$ & $20.4(7.4)$ & $27.5(11.1)$ & $30.8(11.9)$ & $41.1(14.5)$ & $27.7(12.9)$ \\
\hline Mean age of diagnosis, years (SD) & $21.4(4.3)$ & $30.9(5.3)$ & $36.6(7.7)$ & $43.4(10.7)$ & $53.5(12.1)$ & $37.8(12.9)$ \\
\hline $\begin{array}{l}\text { Mean time from first symptoms to diagnosis, } \\
\text { years }\end{array}$ & 4.4 & 10.5 & 9.1 & 12.6 & 12.4 & 10.1 \\
\hline Mean duration of disease, years (SD) & $7.3(4.1)$ & $14.2(7.6)$ & $17.2(11.5)$ & $23.6(11.7)$ & $22.9(14.1)$ & $17.7(11.8)$ \\
\hline Mean number of headache days per month (SD) & $11.6(9.6)$ & $11.6(9.6)$ & $10.8(7.8)$ & $14.0(9.6)$ & $14.8(11.8)$ & $12.4(9.5)$ \\
\hline Episodic migraine, $n$ (\% of age group) & $\begin{array}{l}17 \\
(68.0 \%)\end{array}$ & $\begin{array}{l}27 \\
(67.5 \%)\end{array}$ & $\begin{array}{l}45 \\
(71.4 \%)\end{array}$ & $\begin{array}{l}28 \\
(59.6 \%)\end{array}$ & $\begin{array}{l}18 \\
(56.3 \%)\end{array}$ & $135(65.2 \%)$ \\
\hline Chronic migraine, $n$ (\% of age group) & $8(32.0 \%)$ & $\begin{array}{l}13 \\
(32.5 \%)\end{array}$ & $\begin{array}{l}18 \\
(28.6 \%)\end{array}$ & $\begin{array}{l}19 \\
(40.4 \%)\end{array}$ & $\begin{array}{l}14 \\
(43.8 \%)\end{array}$ & $72(34.8 \%)$ \\
\hline
\end{tabular}

Demographics are presented for each age group and for overall respondents, the latter inclusive of all age groups.

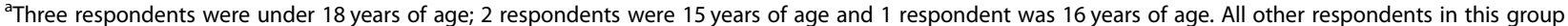
were $22-29$ years of age.

${ }^{\mathrm{b}}$ Two respondents were aged 70 and 1 respondent was aged 76 . All other respondents in this group were 60-68 years of age.

'Values for each group = mean age of diagnosis - mean age of onset. Hence, SD were not calculable for this variable.

$N / n$ Number of patients, SD Standard Deviation 


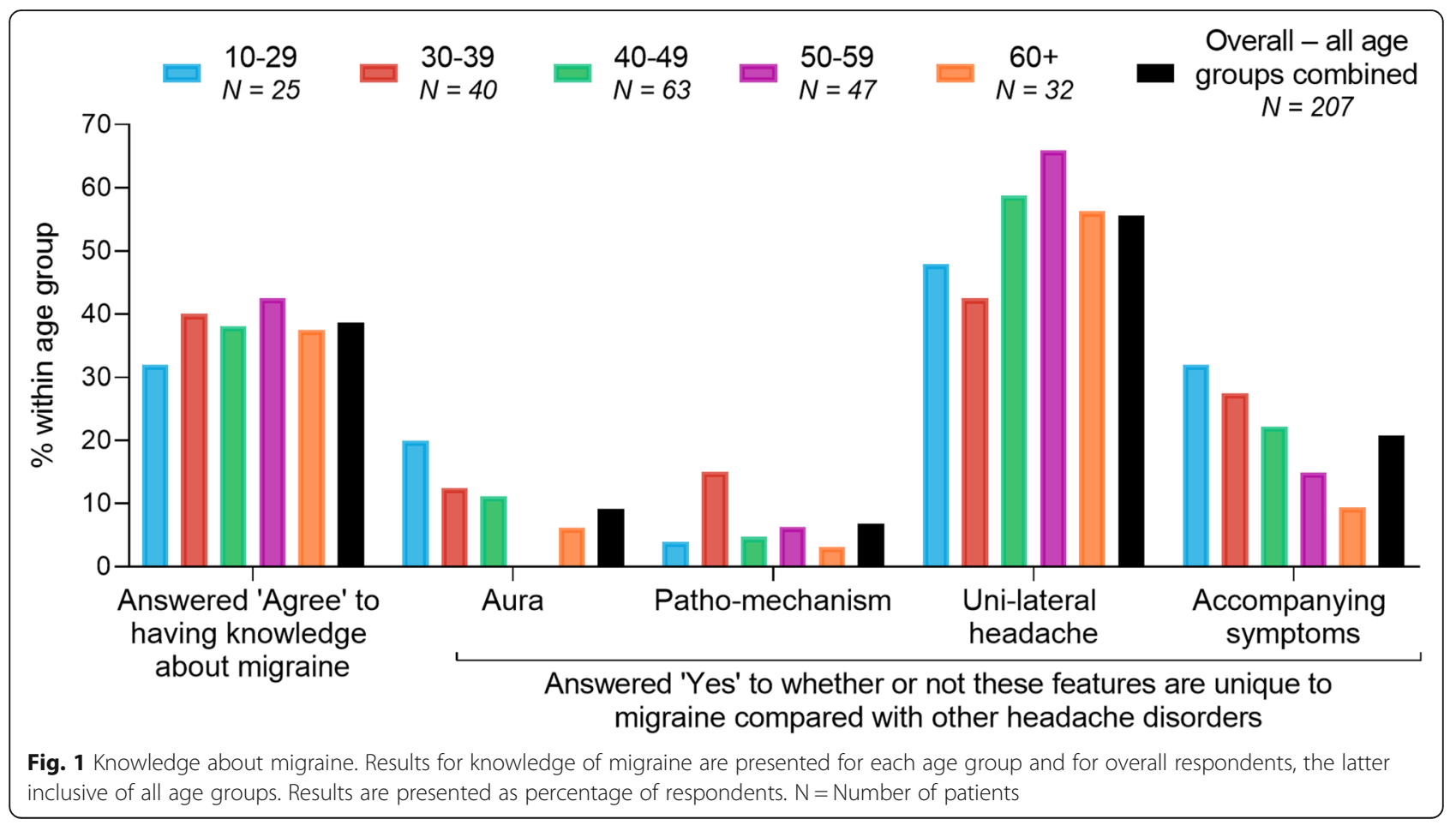

approximately half of patients regarded unilateral headache as a unique feature of migraine (Fig. 1).

\section{Utilization of medical services for migraine and cost of medication}

Results related to utilization of medical services and cost of medication are presented in Table 2. Among respondents, a mean of approximately four hospitals were visited for migraine treatment prior to the current hospital. There was a greater mean number of visited hospitals in older compared with younger patients. Representation of these data by MIDAS grade rather than age group revealed that those in MIDAS grades III and IV had reported the highest mean number of hospitals visited (4.4 [SE=1.3] and $4.1[\mathrm{SE}=0.4]$, respectively), compared with those in grades I and II (2.1 [SE=0.5] and 3.3 [SE=1.6], respectively). Approximately half of respondents overall regularly visited hospital in the past for treatment of migraine. Overall, patients spent on average 1,432,500 Korean Won a year on medication for migraine, with those over 60 spending notably less than other age groups. The majority of patients had a history of visiting a neurology clinic. Approximately half of the respondents had experience of visiting an emergency room (ER), and a quarter had experience of hospitalization. Among Magnetic Resonance Imaging (MRI), Computerized Tomography (CT), Transcranial Doppler (TCD), and Electroencephalogram (EEG), MRI was the most common diagnostic test for migraine, followed by CT, TCD and EEG. There was a notable increase with MRI as a diagnostic test with increasing age group. Approximately one-third of patients overall were satisfied with the doctor-patient relationship in previous hospitals, with notably less satisfaction in the 50-59 group compared with other age groups. Specifically, satisfaction was highest for explanation of migraine offered and lowest for effectiveness of treatment.

\section{Migraine-related disability, quality of life, and pain severity}

Disability and quality of life were assessed with MIDAS and MSQv2.1, respectively. As revealed by MIDAS, the overall mean number of headache days in the previous 3 months reported by respondents was $37.2(\mathrm{SE}=2.0)$. The overall mean MIDAS score was 48.4 (Fig. 2). The overall mean MSQ total score was 47.7, MSQ RR was 42.1, MSQ RP was 54.2, and MSQ EF was 52.2. Using a 0-10 numeric rating scale, with 10 representing the most severe level of pain, overall mean pain severity was reported at 5.9 (Fig. 2). Some aspects of quality of life, specifically the MSQ total and RR domain scores, were notably higher and the pain severity notably lower in the $60+$ group compared with all other age groups (Fig. 2). Narrative descriptions of migraine pain, psychological difficulties, emotional effects, difficulties arising from accompanied symptoms, and daily life provided by respondents portray their personal experiences with migraine (Additional file 1). 
Table 2 Prior utilization of medical services and cost of medication for migraine

\begin{tabular}{|c|c|c|c|c|c|c|}
\hline & $10-29$ & $30-39$ & $40-49$ & $50-59$ & $60+$ & Overall - all age groups combined \\
\hline \multicolumn{7}{|l|}{ Variable } \\
\hline Number of patients, $N$ (\% of total patients) & $25(12.1 \%)$ & $40(19.3 \%)$ & $63(30.4 \%)$ & $47(22.7 \%)$ & $32(15.5 \%)$ & $207(100 \%)$ \\
\hline Mean number of hospitals visited excluding current one (SE) & $2.6(0.4)$ & $3.1(0.6)$ & $4.1(0.9)$ & $4.6(0.8)$ & $4.6(1.2)$ & $3.9(0.4)$ \\
\hline Regular past visits to hospital ${ }^{a}, n$ (\% of age group) & $11(44.0)$ & $21(52.5)$ & $26(41.3)$ & $24(51.1)$ & $15(46.9)$ & $97(46.9)$ \\
\hline Mean annual cost of medication in Korean Won, million (SE) & $1.4(0.5)$ & $1.5(0.3)$ & $1.5(0.2)$ & $1.7(0.3)$ & $1.0(0.2)$ & $1.4(0.1)$ \\
\hline \multicolumn{7}{|l|}{ Experience of: } \\
\hline Visiting a neurology clinic, $n$ (\% of age group) & $17(68.0)$ & $27(67.5)$ & $43(68.3)$ & $36(76.6)$ & $24(75.0)$ & $147(71.0)$ \\
\hline ER visit, $n$ (\% of age group) & $16(64.0)$ & $21(52.5)$ & $24(38.1)$ & $26(55.3)$ & $13(40.6)$ & $100(48.3)$ \\
\hline Hospitalisation, $n$ (\% of age group) & $9(36.0)$ & $8(20.0)$ & $14(22.2)$ & $11(23.4)$ & $8(25.0)$ & $50(24.2)$ \\
\hline \multicolumn{7}{|l|}{ Diagnostic tests } \\
\hline$M R I, n$ (\% of age group) & $11(44.0)$ & $22(55.0)$ & $41(65.1)$ & $33(70.2)$ & $23(71.9)$ & $130(62.8)$ \\
\hline$C T, n$ (\% of age group) & $12(48.0)$ & $23(57.5)$ & $32(50.8)$ & $26(55.3)$ & $14(43.8)$ & $107(51.7)$ \\
\hline$T C D, n$ (\% of age group) & $8(32.0)$ & $18(45.0)$ & $26(41.3)$ & $23(48.9)$ & $11(34.4)$ & $86(41.6)$ \\
\hline EEG as a diagnostic test, $n$ (\% of age group) & $10(40.0)$ & $13(32.5)$ & $21(33.3)$ & $21(44.7)$ & $12(37.5)$ & $77(37.2)$ \\
\hline \multicolumn{7}{|l|}{ Satisfaction with prior doctor-patient relationships, $n$ (\% of age group) } \\
\hline Overall & $8(32.0)$ & $12(30.0)$ & $20(31.8)$ & $10(21.3)$ & $11(34.4)$ & $61(29.5)$ \\
\hline Explanation of migraine & $10(40.0)$ & $13(32.5)$ & $27(42.9)$ & $13(27.7)$ & $11(34.4)$ & $74(35.8)$ \\
\hline Emotional support & $11(44.0)$ & $11(27.5)$ & $22(34.9)$ & $12(25.5)$ & $14(43.8)$ & $70(33.8)$ \\
\hline Effective treatment & $5(20.0)$ & $11(27.5)$ & $17(27.0)$ & $12(25.5)$ & $11(34.4)$ & $56(27.1)$ \\
\hline Devotion of time & $9(36.0)$ & $11(27.5)$ & $19(30.2)$ & $13(27.7)$ & $14(43.8)$ & $66(31.9)$ \\
\hline
\end{tabular}

Results for number of prior hospitals visited excluding the current one, regular past visits to hospital, annual cost of medication, medical services used, diagnostic tests used, and satisfaction with prior doctor-patient relationships are presented for each age group and for overall respondents, the latter inclusive of all age groups

${ }^{\mathrm{a}}$ Respondents who did not visit hospital regularly only visited when they were experiencing a headache. Those who visited regularly did so even in the absence of a headache and on average once every two months ER Emergency Room, MRI Magnetic Resonance Imaging, CT Computerized Tomography, TCD Transcranial Doppler, EEG Electroencephalogram, $N / n$ Number of patients, SE Standard Error

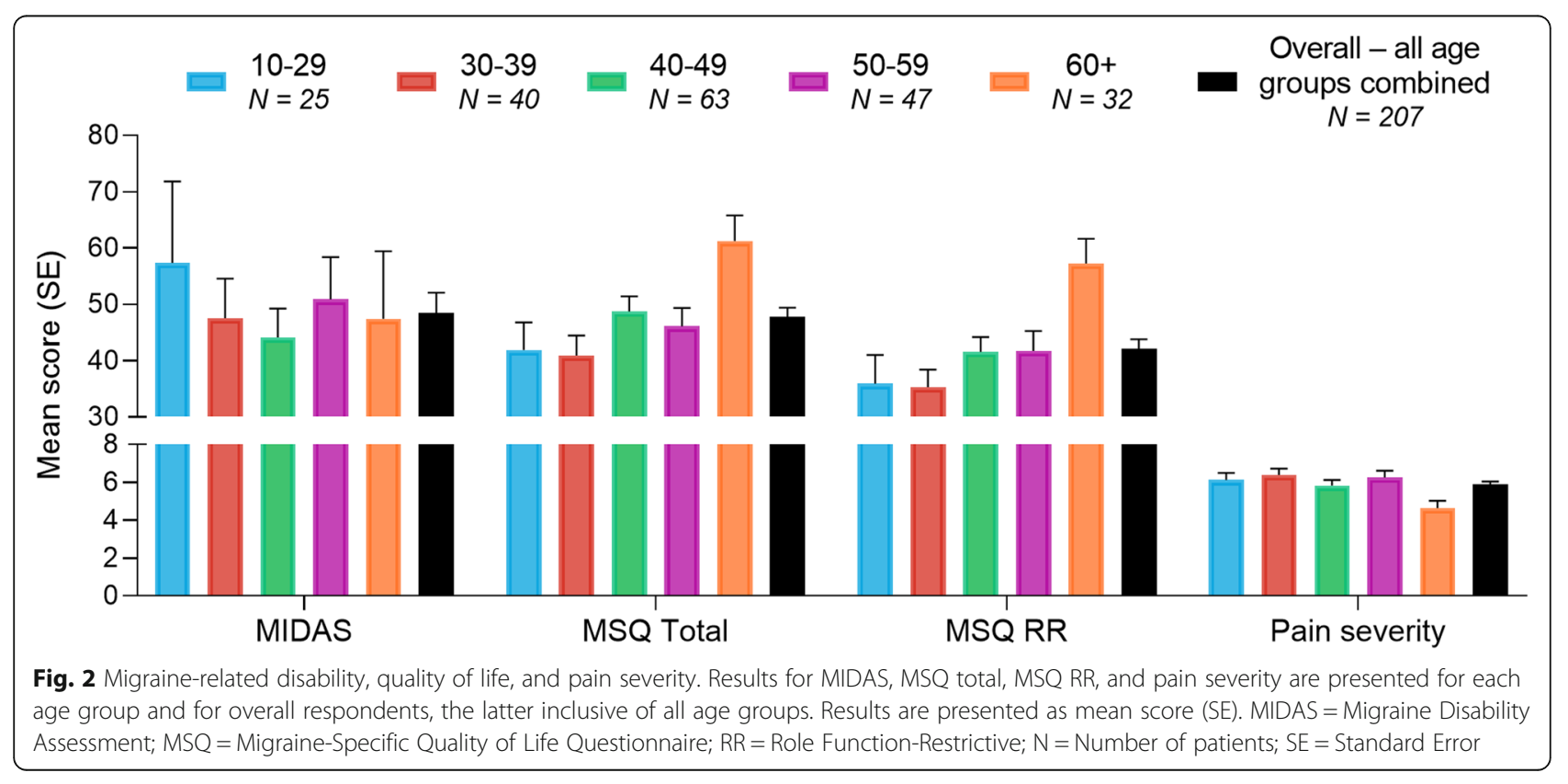




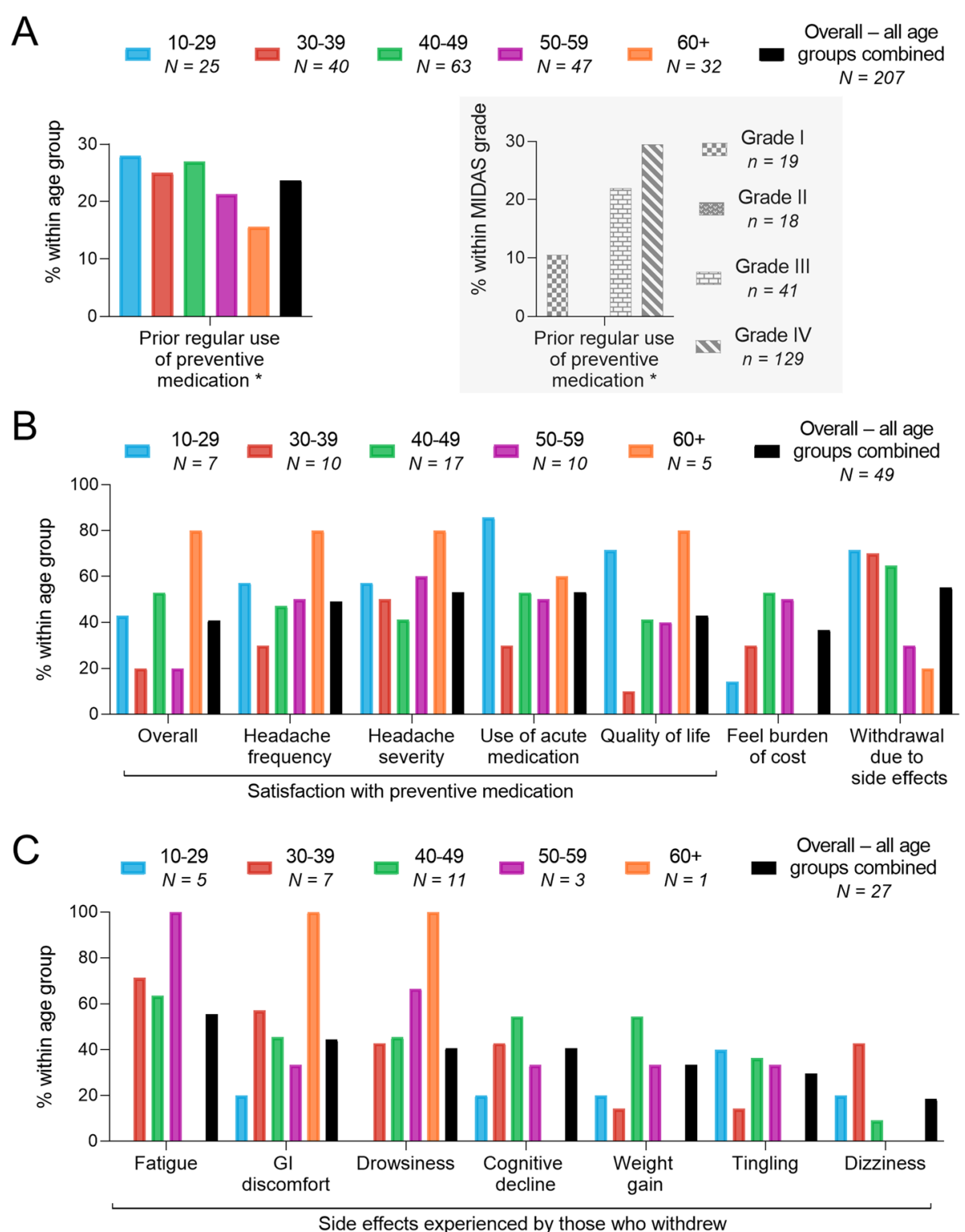

Fig. 3 Past experience with preventive medication for migraine. Results for (a) prior regular use of preventive medication, (b) satisfaction with preventive medication, burden of cost, and withdrawal due to side effects, and (c) side effects experienced by those who withdrew are presented for each age group (and MIDAS grade group in (A)) and for overall respondents, the latter inclusive of all age groups. Results are presented as percentage of respondents. MIDAS = Migraine Disability Assessment; $\mathrm{Gl}=$ Gastro-intestinal; $\mathrm{N}=$ Number of patients. * Respondents who did not take preventive medication regularly only took it when they were experiencing a headache. Those who took preventive medication regularly did so even in the absence of a headache

Past experience with preventive medication for migraine Approximately one-quarter of patients overall reported having used preventive medication regularly prior to visiting their current hospital (Fig. 3a). Reported use or non-use of preventive medication was based on the patient's perception and not medical and/or prescription records. The $60+$ group reported the lowest levels and the 10-29 group the highest levels of prior regular use of preventive medication (Fig. 3a). Representation of these data by MIDAS grade rather than age group revealed that approximately one-third of those in the MIDAS grade IV had regularly taken preventive medication in the past (Fig. 3a; grey box). Less than half of patients with prior experience of preventive medication were satisfied overall with such treatment, with low numbers observed regarding headache frequency, headache severity, use of acute medication, and quality of life specifically. Satisfaction was also particularly low regarding burden of cost with the use of preventive medication, with a notably lower burden reported by the $60+$ 
Table 3 Past experience with acute medication for migraine

\begin{tabular}{lcccccc}
\hline & $\mathbf{1 0 - 2 9}$ & $\mathbf{3 0 - 3 9}$ & $\mathbf{4 0 - 4 9}$ & $\mathbf{5 0 - 5 9}$ & $\mathbf{6 0 +}$ & Overall - all age groups combined \\
\hline Variable & & & & & & \\
$\quad$ Number of patients, N (\% of total patients) & $25(12.1 \%)$ & $40(19.3 \%)$ & $63(30.4 \%)$ & $47(22.7 \%)$ & $32(15.5 \%)$ & $207(100 \%)$ \\
Satisfaction with acute medication ${ }^{a}, n$ (\% of age group) & & & & & \\
$\quad$ Overall & $3(12.0)$ & $12(30.0)$ & $17(27.0)$ & $11(23.4)$ & $13(40.6)$ & $56(27.1)$ \\
Free of headache within $2 h$ & $6(24.0)$ & $21(52.5)$ & $21(33.3)$ & $23(48.9)$ & $17(53.1)$ & $88(42.5)$ \\
Free of accompanying symptoms within $2 h$ & $6(24.0)$ & $18(45.0)$ & $22(34.9)$ & $24(51.1)$ & $17(53.1)$ & $87(42.0)$ \\
24-h sustained effect & $6(24.0)$ & $14(35.0)$ & $19(30.2)$ & $17(36.2)$ & $13(40.6)$ & $69(33.3)$ \\
Feel burden of cost & $6(24.0)$ & $10(25.0)$ & $17(27.0)$ & $12(25.5)$ & $4(12.5)$ & $49(23.7)$ \\
\hline
\end{tabular}

Results for satisfaction with acute medication and burden of cost are presented for each age group and for overall respondents, the latter inclusive of all age groups.

${ }^{a}$ Acute medications included prescription-only and over-the-counter medications. $N / n$ Number of patients

group compared with all other age groups (Fig. 3b). Of the 49 patients who had taken preventive medication in the past, approximately half withdrew at some point due to the side effects (Fig. 3b). Of those who withdrew, the most common side effect among those listed was fatigue, followed by gastro-intestinal (GI) discomfort, drowsiness, cognitive decline, weight gain, tingling, and dizziness (Fig. 3c).

\section{Past experience with acute medication for migraine}

Upon assessment of overall satisfaction with acute medication taken prior to visiting current hospitals, approximately one-quarter of respondents were satisfied overall with such treatment (Table 3). Satisfaction was higher in the $60+$ group compared with all other age groups. Satisfaction was low regarding being free of both headache and accompanying symptoms within $2 \mathrm{~h}$, as well as a 24h sustained effect specifically (Table 3 ). Satisfaction was also particularly low regarding burden of cost with the use of acute medication, with a notably lower burden reported by the $60+$ group compared with all other age groups (Table 3 ).

\section{Discussion}

The results of this recent survey demonstrate that there are significant issues and unmet needs for Korean patients with migraine regarding diagnosis, awareness, and treatment. These include a substantial diagnostic lag, dissatisfaction with clinical management of the disease, frequent visits to hospital, and burden of cost. The burden of disease experienced by patients is evident by their significant levels of disability, pain severity, and reduced quality of life.

The respondent population were patients in specialized headache clinics, which could not be fully representative of those with migraine in the general population. The mean age of onset in the overall population of respondents was close to 30 years of age, ranging from 8 to 61 years old. Differences between groups in the age of onset is most likely due to the difficulty of recalling memories from more than 20 years ago, and selection bias. Overall, the average time from first symptoms to diagnosis was 10.1 years. Delay in diagnosis could be due to insufficient awareness of the characteristics of migraine both by non-specialist physicians and by patients [30]. The diagnostic criteria of migraine in the ICHD appear straightforward and clear, however, due to the diversity of migraine symptoms among patients and among attacks for an individual patient, some physicians are unsure of the diagnosis of migraine. Many patients also take painkillers during the early phase of migraine attacks and, as a result, their headaches frequently do not fit the diagnostic criteria of migraine. Another possible contributory factor to delayed diagnosis is unreliable information from patients regarding their headache history. Without detailed information on the characteristics of migraine headaches and any associated symptoms experienced, accurate diagnosis can be a challenge. Lack of accurate and complete information from patients on the history of their migraine could be caused in part by limited knowledge about the disease. More than half of overall respondents believed that unilateral headache is a unique feature of migraine. This commonly shared belief among patients and possibly physicians too could be in part influenced by the fact that the Chinese character for migraine, used throughout East Asian countries, directly translates to 'one-sided head pain'. In addition, the results of the survey show that the majority of respondents did not know that migraine differs from other headache disorders with regards to aura, patho-mechanism, and accompanying symptoms. This could have impacted diagnosis as aura and accompanying symptoms such as nausea or vomiting are used in the diagnosis of migraine according to ICHD-3 criteria. In support of this, the survey results show that the 10-29 age group was amongst the most informed about unilateral headache, aura, and 
accompanying symptoms, and had the shortest diagnostic lag among all age groups. It could also be the case that patients did not have knowledge about aura due to lack of experience of it. Indeed, a study has shown that only $13 \%$ of Korean patients with migraine have aura symptoms [31].

A previous study across 8 Asian countries reported that $36 \%$ of patients had visited emergency rooms due to migraine [23]. The current study reveals that, for Korean patients specifically, the proportion is much higher at $48 \%$. MRI was the most common diagnostic test among respondents, followed by CT, possibly due to MRI being more sensitive than CT in identifying intracranial pathology, and more generally preferred for the evaluation of headaches [32-34]. Neuroimaging is not usually warranted for patients who meet the diagnostic criteria for migraine and have normal findings on a neurologic examination. Neuroimaging may also contribute to a delay in diagnosis and treatment if exact diagnosis and proper education about migraine are not subsequently provided [35]. Some patients, however, might insist on the use of neuroimaging, as it can relieve anxiety about underlying pathology and thus improve quality of life.

Assessment of the doctor-patient relationship in patients' previous hospitals revealed that there was significant dissatisfaction among patients. Specifically, less than half of patients were satisfied with the explanation of migraine, emotional support, effectiveness of treatment, and devotion of physician's time. In the Korean medical system, there is no method of compensation for counselling, education, and evaluation of headache severity. Along with the fact that Korean physicians usually spend no more than 10 min caring for one patient, including first-visit patients, this could in part explain the dissatisfaction with prior doctor-patient relationships. The lack of patient knowledge about migraine also revealed in the survey results could be partly related to the low satisfaction with the explanation of migraine. Studies have shown that effective communication between physicians and patients plays a role in determining diagnosis, treatment compliance and medical outcomes [3638]. Patient dissatisfaction with this relationship is an area of concern for physicians, leading to the creation of strategies and tools to facilitate this communication network [37].

The components of the survey related to patients' past experience with medication clearly demonstrate unmet treatment needs for Korean patients. Only $23.7 \%$ of respondents overall had regularly taken preventive medication in the past, despite reporting a mean number of 12.4 headache days per month. Such poor treatment optimization could be potentially responsible, at least in part, for the high levels of disability (MIDAS) and pain severity, along with poor quality of life (MSQ) reported by respondents. Indeed, only $29.5 \%$ of respondents in MIDAS grade IV (severe disability) had regularly taken preventive medication in the past. Respondents in MIDAS grades III and IV also reported the highest numbers of hospitals visited in the past, compared with respondents in MIDAS grades I and II, which hints at an association between prolonged, inadequate management of migraine and higher levels of disability. The reported low levels of satisfaction with both preventive and acute medications among respondents could be a reflection of such un-optimal management of migraine. Thus, as reported in other studies including analyses in Asian countries [23, 39-42], there are clear unmet preventive treatment needs for Korean patients with migraine, particularly for those in most need of them. The 60+ group had the lowest prior regular use of preventive treatment. This could be explained by the development and availability of more preventive treatments in recent years, along with the natural evolution of migraine to a less disabling headache type with age [43, 44]. Lack of efficacy and undesirable side effects of preventive medication reported were in line with a previous study across six countries [45]. Similar to other findings, the proportion of respondents dissatisfied with the cost of preventive treatment was relatively low in comparison to other aspects of preventive medication use [45], and likely owing in part to the availability of generic and cheaper medications. Less than half of respondents were satisfied with the relief they had obtained within $2 \mathrm{~h}$ of taking acute medication in terms of being free of headache and accompanying symptoms. Such effects, along with having 24-h sustained relief, are attributes of acute treatment rated as important by patients [46-48].

We would like to note some possible limitations of the study. First, the short timeframe in which the surveys were completed may have limited the number of participants. Second, the cross-sectional nature of the study made it difficult to investigate causal relationships between variables. Third, the setting of specialized headache clinics may have introduced an element of selection bias.

\section{Conclusion}

In conclusion, the results of our survey confirm the significant burden that Korean patients with migraine experience and the critical unmet needs with regards to diagnosis and treatment. Patient-centric intervention to reduce the diagnostic lag, increase awareness and understanding of migraine, optimize the use of medical services, enhance doctor-patient relationships and the 
management of migraine should be implemented to alleviate the burden of migraine.

\section{Abbreviations}

CT: Computerized Tomography; EEG: Electroencephalogram; EF: Emotional Function; ER: Emergency Room; Gl: Gastro-Intestinal; ICHD: International Classification of Headache Disorders; MIDAS: Migraine Disability Assessment; MRI: Magnetic Resonance Imaging; MSQ: Migraine-Specific Quality of Life Questionnaire; RP: Role Function-Preventive; RR: Role Function-Restrictive; SE: Standard Error; SD: Standard Deviation; TCD: Transcranial Doppler

\section{Supplementary Information}

The online version contains supplementary material available at https://doi. org/10.1186/s10194-021-01250-6.

\section{Additional file 1.}

\section{Acknowledgements}

The authors thank Hankook Research Ltd. for their help in creating the survey, gathering the responses, and compiling the data. We thank Sarah Roche, PhD, an employee of Eli Lilly and Company, who provided writing assistance.

\section{Authors' contributions}

BKK, MKC, SJY, and SJC contributed to conception and design of the work. BKK, MKC, and SJC contributed to acquisition of data for the work. SJY and $\mathrm{JHH}$ contributed to analysis of data for the work. BKK, SJY, GDA, JHH and SJC contributed to interpretation of data for the work. All authors contributed to drafting and/or critical revision of the work for important intellectual content. The author(s) read and approved the final manuscript.

\section{Funding}

This study was funded by Eli Lilly and Company and Korean Headache Society.

\section{Availability of data and materials}

Anonymized datasets generated and/or analyzed during the current study are available upon reasonable request and following the acquisition of necessary permissions.

\section{Declarations}

\section{Ethics approval and consent to participate}

Participants were recruited by their neurologists. Conducting of surveys is subject to Institutional Review Board exemption in Korea, but approval is required for preparation of a publication. Prior to participation, patients provided written consent to use the results of the survey for statistical purposes. Approval for preparation of this manuscript was granted by the Institutional Review Board of Nowon Eulji Medical Center (Approval No 2020-06-009). Survey data were handled confidentially, and anonymity of respondents was maintained throughout the study.

\section{Consent for publication}

Not applicable.

\section{Competing interests}

BKK has received consulting fees and honoraria from the Center for New Health Technology Assessment, National Pension Service, Eli Lilly, Allergan, Teva, Lundbeck, Novartis, Sanofi Korea, SK Pharm, Yuyu Pharm, and Ildong Pharm during the last two years. MKC was involved as a site investigator for a multicenter trial sponsored by Otsuka Korea, Allergan, Ildong Pharmaceutical Co., LTD, Novartis International AG, and Eli Lilly and Company. He has worked as an advisory member for Teva, and has received lecture honoraria from Allergan Korea, Handok-Teva and Yuyu Pharmaceutical Company. SJY is a full-time employee of Eli Lilly and Company. GDA is a full-time employee and a minor stockholder of Eli Lilly and Company. JHH is a full-time employee of Eli Lilly and Company. SJC was involved as a site investigator for a multicenter trial sponsored by Otsuka Korea, Allergan, Ildong Pharmaceutical Co., LTD, Novartis International AG, Eli Lilly and Company,
Parexel Korea Co., Ltd., and has received lecture honoraria from Allergan Korea, Whanln Pharm Co., LTD, Handok-Teva, Yuyu Pharmaceutical Company, and SK Chemicals.

\section{Author details}

${ }^{1}$ Department of Neurology, Nowon Eulji Medical Center, Eulji University

School of Medicine, Seoul, South Korea. '2Department of Neurology,

Severance Hospital, Yonsei University School of Medicine, Seoul, South Korea.

${ }^{3}$ Lilly Korea Ltd., Seoul, South Korea. ${ }^{4}$ Eli Lilly and Company, Sesto Fiorentino

(FI), Italy. ${ }^{5}$ Department of Neurology, Dongtan Sacred Heart Hospital, Hallym University College of Medicine, Hwaseong, South Korea.

Received: 29 October 2020 Accepted: 29 April 2021

Published online: 24 May 2021

\section{References}

1. Wijeratne T, Grisold W, Dodick D, Carroll W (2019) World brain day 2019: migraine, the painful truth. Lancet Neurol 18(10):914. https://doi.org/10.10 6/S1474-4422(19)30281-9

2. Woldeamanuel YW, Cowan RP (2017) Migraine affects 1 in 10 people worldwide featuring recent rise: a systematic review and meta-analysis of community-based studies involving 6 million participants. J Neurol Sci 372: 307-315. https://doi.org/10.1016/j.jns.2016.11.071

3. GBD (2017) Disease and injury incidence and prevalence collaborators (2018) global, regional, and national incidence, prevalence, and years lived with disability for 354 diseases and injuries for 195 countries and territories, 1990-2017: a systematic analysis for the global burden of disease study 2017. Lancet. 392(10159):1789-1858

4. Steiner TJ, Stovner LJ, Vos T, Jensen R, Katsarava Z (2018) Migraine is first cause of disability in under 50s: will health politicians now take notice? J Headache Pain 19(1):17

5. Steiner TJ, Stovner LJ, Katsarava Z, Lainez JM, Lampl C, Lanteri-Minet M et al (2014) The impact of headache in Europe: principal results of the Eurolight project. J Headache Pain 15(1):31. https://doi.org/10.1186/1129-2377-15-31

6. Leonardi M, Raggi A (2019) A narrative review on the burden of migraine: when the burden is the impact on people's life. J Headache Pain 20(1):41. https://doi.org/10.1186/s10194-019-0993-0

7. Adams AM, Serrano D, Buse DC, Reed ML, Marske V, Fanning KM, Lipton RB (2015) The impact of chronic migraine: the chronic migraine epidemiology and outcomes (CaMEO) study methods and baseline results. Cephalalgia. 35(7):563-578. https://doi.org/10.1177/0333102414552532

8. Lipton RB, Manack Adams A, Buse DC, Fanning KM, Reed ML (2016) A comparison of the chronic migraine epidemiology and outcomes (CaMEO) study and American Migraine Prevalence and Prevention (AMPP) study: demographics and headache-related disability. Headache. 56(8):1280-1289. https://doi.org/10.1111/head.12878

9. Buse DC, Fanning KM, Reed ML, Murray S, Dumas PK, Adams AM, Lipton RB (2019) Life with migraine: effects on relationships, career, and finances from the chronic migraine epidemiology and outcomes (CaMEO) study. Headache. 59(8):1286-1299. https://doi.org/10.1111/head.13613

10. Lampl C, Thomas H, Tassorelli C, Katsarava Z, Lainez JM, Lanteri-Minet M et al (2016) Headache, depression and anxiety: associations in the Eurolight project. J Headache Pain 17(1):59. https://doi.org/10.1186/s10194-016-0649-2

11. Song TJ, Cho SJ, Kim WJ, Yang Kl, Yun CH, Chu MK (2019) Sex differences in prevalence, symptoms, impact, and psychiatric comorbidities in migraine and probable migraine: a population-based study. Headache. 59(2):215-223. https://doi.org/10.1111/head.13470

12. Chen P-K, Wang S-J (2018) Non-headache symptoms in migraine patients. F1000Res 7:188

13. Wang S-J, Chen P-K, Fuh J-L (2010) Comorbidities of migraine. Front Neurol 1:16

14. Yang CP, Wang SJ (2017) Sleep in patients with chronic migraine. Curr Pain Headache Rep 21(9):39. https://doi.org/10.1007/s11916-017-0641-9

15. Vetvik KG, MacGregor EA (2017) Sex differences in the epidemiology, clinical features, and pathophysiology of migraine. Lancet Neurol 16(1):76-87. https://doi.org/10.1016/S1474-4422(16)30293-9

16. Peng KP. Wang SJ (2014) Epidemiology of headache disorders in the Asiapacific region. Headache. 54(4):610-618. https://doi.org/10.1111/head.12328

17. Chu MK, Kim DW, Kim BK, Kim JM, Jang TW, Park JW, Lee KS, Cho SJ (2013) Gender-specific influence of socioeconomic status on the prevalence of 
migraine and tension-type headache: the results from the Korean headache survey. J Headache Pain 14(1):82. https://doi.org/10.1186/1129-2377-14-82

18. Kim BK, Chu MK, Lee TG, Kim JM, Chung CS, Lee KS (2012) Prevalence and impact of migraine and tension-type headache in Korea. J Clin Neurol 8(3): 204-211. https://doi.org/10.3988/jcn.2012.8.3.204

19. Kim BK, Chung YK, Kim JM, Lee KS, Chu MK (2013) Prevalence, clinical characteristics and disability of migraine and probable migraine: a nationwide population-based survey in Korea. Cephalalgia. 33(13):11061116. https://doi.org/10.1177/0333102413484990

20. Roh JK, Kim JS, Ahn YO (1998) Epidemiologic and clinical characteristics of migraine and tension-type headache in Korea. Headache. 38(5):356-365. https://doi.org/10.1046/j.1526-4610.1998.3805356.x

21. Choi YJ, Kim BK, Chung PW, Lee MJ, Park JW, Chu MK, Ahn JY, Kim BS, Song TJ, Sohn JH, Oh K, Lee KS, Kim SK, Park KY, Chung JM, Moon HS, Chung CS, Cho SJ (2018) Impact of cluster headache on employment status and job burden: a prospective cross-sectional multicenter study. J Headache Pain 19(1):78. https://doi.org/10.1186/s10194-018-0911-x

22. Takeshima T, Wan Q, Zhang Y, Komori M, Stretton S, Rajan N, Treuer T, Ueda $\mathrm{K}$ (2019) Prevalence, burden, and clinical management of migraine in China, Japan, and South Korea: a comprehensive review of the literature. J Headache Pain 20(1):111. https://doi.org/10.1186/s10194-019-1062-4

23. Wang SJ, Chung CS, Chankrachang S, Ravishankar K, Merican JS, Salazar G, Siow C, Cheung RTF, Phanthumchinda K, Sakai F (2008) Migraine disability awareness campaign in Asia: migraine assessment for prophylaxis. Headache. 48(9):1356-1365. https://doi.org/10.1111/j.1526-4610.2008.01088.x

24. Park JW, Moon HS, Kim JM, Lee KS, Chu MK (2014) Chronic daily headache in Korea: prevalence, clinical characteristics, medical consultation and management. J Clin Neurol 10(3):236-243. https://doi.org/10.3988/jen.2014.1 0.3 .236

25. Ueda K, Ye W, Lombard L, Kuga A, Kim Y, Cotton S, Jackson J, Treuer T (2019) Real-world treatment patterns and patient-reported outcomes in episodic and chronic migraine in Japan: analysis of data from the Adelphi migraine disease specific programme. J Headache Pain 20(1):68. https://doi. org/10.1186/s10194-019-1012-1

26. Liu R, Yu S, He M, Zhao G, Yang X, Qiao X, Feng J, Fang Y, Cao X, Steiner TJ (2013) Health-care utilization for primary headache disorders in China: a population-based door-to-door survey. J Headache Pain 14(1):47. https://doi. org/10.1186/1129-2377-14-47

27. Stewart WF, Lipton RB, Dowson AJ, Sawyer J (2001) Development and testing of the migraine disability assessment (MIDAS) questionnaire to assess headache-related disability. Neurology. 56(6 Suppl 1):S20-S28. https:// doi.org/10.1212/WNL.56.suppl_1.S20

28. Martin BC, Pathak DS, Sharfman MI, Adelman JU, Taylor F, Kwong WJ, Jhingran P (2000) Validity and reliability of the migraine-specific quality of life questionnaire (MSQ version 2.1). Headache. 40(3):204-215. https://doi. org/10.1046/j.1526-4610.2000.00030.x

29. Bagley CL, Rendas-Baum R, Maglinte GA, Yang M, Varon SF, Lee J, Kosinski M (2012) Validating migraine-specific quality of life questionnaire V2.1 in episodic and chronic migraine. Headache. 52(3):409-421. https://doi.org/1 0.1111/j.1526-4610.2011.01997.x

30. Viticchi G, Silvestrini M, Falsetti L, Lanciotti C, Cerqua R, Luzzi S, Provinciali L, Bartolini M (2011) Time delay from onset to diagnosis of migraine. Headache. 51(2):232-236. https://doi.org/10.1111/j.1526-4610.2010.01778.x

31. Jo NJ, Kim BK (2015) Clinical characteristics of migraine with Aura in Korean: a clinic based study. J Korean Neurol Assoc 33(4):278-281. https://doi.org/1 0.17340/jkna.2015.4.6

32. De Luca GC, Bartleson JD (2010) When and how to investigate the patient with headache. Semin Neurol 30(2):131-144. https://doi.org/10.1055/s-003 0-1249221

33. Evans RW (2001) DIAGNOSTIC TESTING FOR HEADACHE. Med Clin N Am 85(4):865-885. https://doi.org/10.1016/S0025-7125(05)70348-5

34. Kim BS, Kim SK, Kim JM, Moon HS, Park KY, Park JW, Sohn JH, Song TJ, Chu MK, Cha MJ, Kim BK, Cho SJ (2020) Factors associated with incidental neuroimaging abnormalities in new primary headache patients. J Clin Neurol 16(2):222-229. https://doi.org/10.3988/jcn.2020.16.2.222

35. Viticchi G, Silvestrini M, Falsetti L, Lanciotti C, Cerqua R, Luzzi S, Provinciali L, Bartolini M (2011) The role of instrumental examinations in delayed migraine diagnosis. Neurol Sci 32(1):143-144. https://doi.org/10.1007/s1 0072-011-0520-9

36. Purdy RA (2002) Migraine: the doctor-patient link. Results of a needs assessment. Can J Neurol Sci 29(Suppl 2):S3-S7
37. Buse DC, Lipton RB (2008) Facilitating communication with patients for improved migraine outcomes. Curr Pain Headache Rep 12(3):230-236. https://doi.org/10.1007/s11916-008-0040-3

38. Palacios-Cena D, Neira-Martin B, Silva-Hernandez L, Mayo-Canalejo D, Florencio LL, Fernandez-de-Las-Penas C et al (2017) Living with chronic migraine: a qualitative study on female patients' perspectives from a specialised headache clinic in Spain. BMJ Open 7(8):e017851. https://doi. org/10.1136/bmjopen-2017-017851

39. Lipton RB, Bigal ME, Diamond M, Freitag F, Reed ML, Stewart WF, Group AA (2007) Migraine prevalence, disease burden, and the need for preventive therapy. Neurology. 68(5):343-349

40. Dodick DW, Loder EW, Manack Adams A, Buse DC, Fanning KM, Reed ML, Lipton RB (2016) Assessing barriers to chronic migraine consultation, diagnosis, and treatment: results from the chronic migraine epidemiology and outcomes (CaMEO) study. Headache. 56(5):821-834. https://doi.org/1 $0.1111 /$ head.12774

41. Katsarava Z, Mania M, Lampl C, Herberhold J, Steiner TJ (2018) Poor medical care for people with migraine in Europe - evidence from the Eurolight study. J Headache Pain 19(1):10. https://doi.org/10.1186/s10194-018-0839-1

42. Lipton RB, Buse DC, Serrano D, Holland S, Reed ML (2013) Examination of unmet treatment needs among persons with episodic migraine: results of the American Migraine Prevalence and Prevention (AMPP) study. Headache. 53(8):1300-1311. https://doi.org/10.1111/head.12154

43. Nachit-Ouinekh F, Dartigues JF, Chrysostome V, Henry P, Sourgen C, El Hasnaoui A (2005) Evolution of migraine after a 10-year follow-up. Headache. 45(10):1280-1287. https://doi.org/10.1111/j.1526-4610.2005.00259.

44. Bille B (1997) A 40-year follow-up of school children with migraine. Cephalalgia. 17(4):488-491; discussion 7. https://doi.org/10.1046/j.1468-2 982.1997.1704488.x

45. Blumenfeld AM, Bloudek LM, Becker WJ, Buse DC, Varon SF, Maglinte GA, Wilcox TK, Kawata AK, Lipton RB (2013) Patterns of use and reasons for discontinuation of prophylactic medications for episodic migraine and chronic migraine: results from the second international burden of migraine study (IBMS-II). Headache. 53(4):644-655. https://doi.org/10.1111/head.12055

46. Lanteri-Minet M (2005) What do patients want from their acute migraine therapy? Eur Neurol 53(Suppl 1):3-9. https://doi.org/10.1159/000085036

47. Lipton RB, Hamelsky SW, Dayno JM (2002) What do patients with migraine want from acute migraine treatment? Headache. 42(Suppl 1):3-9. https:// doi.org/10.1046/j.1526-4610.2002.0420s1003.x

48. Malik SN, Hopkins M, Young WB, Silberstein SD (2006) Acute migraine treatment: patterns of use and satisfaction in a clinical population. Headache. 46(5):773-780. https://doi.org/10.1111/j.1526-4610.2006.00437.x

\section{Publisher's Note}

Springer Nature remains neutral with regard to jurisdictional claims in published maps and institutional affiliations.

Ready to submit your research? Choose BMC and benefit from:

- fast, convenient online submission

- thorough peer review by experienced researchers in your field

- rapid publication on acceptance

- support for research data, including large and complex data types

- gold Open Access which fosters wider collaboration and increased citations

- maximum visibility for your research: over $100 \mathrm{M}$ website views per year

At $\mathrm{BMC}$, research is always in progress.

Learn more biomedcentral.com/submissions 